\title{
Contributions of tropodithietic acid and biofilm formation to the probiotic activity of Phaeobacter inhibens
}

\author{
Wenjing Zhao ${ }^{1,4}$, Christine Dao ${ }^{2,5}$, Murni Karim, ${ }^{3,6}$, Marta Gomez-Chiarri', David Rowley ${ }^{3}$ and David R. Nelson ${ }^{1 *}$
}

\begin{abstract}
Background: The probiotic bacterium Phaeobacter inhibens strain S4Sm, isolated from the inner shell surface of a healthy oyster, secretes the antibiotic tropodithietic acid (TDA), is an excellent biofilm former, and increases oyster larvae survival when challenged with bacterial pathogens. In this study, we investigated the specific roles of TDA secretion and biofilm formation in the probiotic activity of S4Sm.
\end{abstract}

Results: Mutations in CIpX (ATP-dependent ATPase) and exoP (an exopolysaccharide biosynthesis gene) were created by insertional mutagenesis using homologous recombination. Mutation of $c / p X$ resulted in the loss of TDA production, no decline in biofilm formation, and loss of the ability to inhibit the growth of Vibrio tubiashii and Vibrio anguillarum in co-colonization experiments. Mutation of exoP resulted in a 60\% decline in biofilm formation, no decline in TDA production, and delayed inhibitory activity towards Vibrio pathogens in co-colonization experiments. Both $C_{P X} X$ and exoP mutants exhibited reduced ability to protect oyster larvae from death when challenged by Vibrio tubiashii. Complementation of the $C I p X$ and exoP mutations restored the wild type phenotype. We also found that pre-colonization of surfaces by S4Sm was critical for this bacterium to inhibit pathogen colonization and growth.

Conclusions: Our observations demonstrate that probiotic activity by $P$. inhibens $\mathrm{S} 4 \mathrm{Sm}$ involves contributions from both biofilm formation and the production of the antibiotic TDA. Further, probiotic activity also requires colonization of surfaces by S4Sm prior to the introduction of the pathogen.

Keywords: Phaeobacter inhibens, Tropodithietic acid, Biofilm formation, Probiotic, Marine pathogens, Vibrio tubiashii, Vibrio anguillarum, Oyster disease, ClpX, ExoP

\section{Background}

Infections by pathogenic marine bacteria are a major problem for both the shellfish and finfish aquaculture industries, causing severe disease and high mortality, which seriously affect aquaculture production and cause significant economic loss [1]. This problem particularly affects the survival and growth of fish and shellfish during the larval and juvenile stages [1,2]. Opportunistic pathogens from the Vibrionaceae and at least one member of the Roseobacter clade cause disease in a variety of shellfish [3, 4]. For example, Vibrio tubiashii, a reemerging pathogen of larval bivalve mollusks that causes

\footnotetext{
*Correspondence: dnelson@uri.edu

'Department of Cell and Molecular Biology, University of Rhode Island, 120

Flagg Rd., Kingston, RI 02881, USA

Full list of author information is available at the end of the article
}

invasive and toxigenic disease, has been responsible for massive mortalities among larval Pacific oysters (Crassostrea gigas) in hatcheries on the west coast of the United States [4]. Additionally, Roseovarius crassostreae, a member of the Roseobacter clade and the causative agent of juvenile or Roseovarius oyster disease (JOD or ROD), can cause high mortalities in juvenile eastern oysters (Crassostrea virginica) in the northeastern United States during the summer when water temperatures are $\geq 20{ }^{\circ} \mathrm{C}$ [5]. Although antibiotics and vaccines can be used to control some infectious diseases in aquaculture, they have some distinct disadvantages and limitations. Use of antibiotics increases the risk of development and transfer of antibiotic resistance [6]. Vaccines, which rely on an adaptive immune response, are only effective for vertebrate organisms and cannot be used to protect shellfish [7]. 
Probiotics represent a promising alternative strategy to control infection and some probiotic strains are already used commonly in aquaculture as biological control agents in finfish and shellfish [8, 9]. For example, the probionts Bacillus subtilis and Bacillus licheniformis are widely used in shrimp aquaculture to provide beneficial effects potentially including improved health and water quality, control of pathogenic bacteria and their virulence, stimulation of the immune system and improved growth [10]. Several Phaeobacter species have been shown to be effective probiotics for both finfish and shellfish. For example, D'Alvise et al. [11] demonstrated that Phaeobacter can be used as a probiotic treatment to reduce the density of the fish pathogen Vibrio anguillarum in cultures of cod larvae, resulting in the reduction of mortality by vibriosis. The probiotic activity was dependent upon the production of tropodithietic acid (TDA) by $P$. gallaeciensis. Further, D'Alvise et al. [12] demonstrated that a different TDA-producing strain of Phaeobacter was able to reduce or eliminate $V$. anguillarum from a combined liquid-surface system. These and other studies strongly suggest that antagonistic interactions by probiotic bacteria against marine pathogens may be useful in protecting commercially important species of shellfish and finfish from infectious disease.

Phaeobacter inhibens is gram-negative $\alpha$-Proteobacteria from the Roseobacter clade. The Roseobacter clade, an important member of the marine microbiota, accounts for $\sim 4 \%$ to as much as $\sim 40 \%$ of bacterial DNA from the ocean and plays an important role in the organic sulfur cycle of the ocean [13-15]. Several species in this clade exhibit inhibitory activity against the growth of marine pathogens, including $V$. anguillarum, $V$. tubiashii and $R$. crassostreae $[11,12,16]$. Additionally, several potentially probiotic species from the Roseobacter clade can be routinely isolated from larval production facilities for turbot [17]. Further, Phaeobacter species are typically excellent biofilm formers, colonizing a variety of surfaces including the walls of rearing tanks, microalgae, the skin of finfish, and the shells of mollusks [12, 18, 19]. Although, biofilm formation is thought to be essential for probiotic activity by a variety of mechanisms including competition for adhesion sites, oxygen, nutrients, and by preventing contact between pathogens and hosts [20], the role of biofilm formation in the probiotic activity of Phaeobacter species against shellfish pathogens has not been thoroughly investigated.

Previously, we isolated $P$. inhibens S4 from the inner shell surface of a healthy oyster [16]. This bacterium is a short rod with 1-2 flagella on one or both poles. It has pleiomorphic morphology and will elongate into long rods and filaments under specific conditions (low salt concentration, static incubation, stationary phase). It can form rosettes and is an excellent biofilm former and a dominant colonizer of surfaces in marine environments. P. inhibens $\mathrm{S} 4 \mathrm{Sm}$ is a spontaneous streptomycin-resistant mutant of the parental S4. When S4Sm was used as a potential probiotic treatment of oyster larvae, it showed strong anti-pathogen activity and increased host survival [16], but the actual mechanisms of probiotic activity used by this isolate are not fully understood.

In this study we examined the roles of biofilm formation and TDA production in probiotic activity of $P$. inhibens $\mathrm{S} 4 \mathrm{Sm}$ in oysters challenged by the pathogen, $V$. tubiashii. In order to determine the contributions of TDA production and biofilm formation to the probiotic activity of S4Sm, mutations in $\operatorname{clp} X$ (which blocks TDA biosynthesis [21]) and an exopolysaccharide biosynthesis gene $($ exoP) (potentially involved in biofilm formation) were created by insertional mutagenesis. The effects of these mutations upon TDA production, biofilm formation and probiotic activity were determined.

\section{Results}

$P$. inhibens S4Sm secretes the antibiotic tropodithietic acid Bioassay-guided fractionation of $P$. inhibens supernatants resulted in the purification of a single secondary metabolite possessing antimicrobial activity. The molecule was identified as tropodithietic acid (TDA) based upon a molecular ion of $[\mathrm{M}+\mathrm{H}]^{+}=213$ [13] and comparison of ${ }^{1} \mathrm{H}$ NMR chemical shift data $\left(500 \mathrm{MHz}, \mathrm{C}_{6} \mathrm{D}_{6}\right)$ with literature values [22] (Additional files 1, 2 and 3). All assays described below were conducted with this purified TDA. UHPLC analysis data (Fig. 1a) confirmed that TDA was present in S4Sm supernatant.

\section{Differential sensitivities of marine pathogens to TDA}

We examined the relative sensitivities of three pathogens of marine organisms, $V$. anguillarum NB10Sm, $V$. tubiashii RE22Sm, and $R$. crassostreae CV919Sm, to P. inhibens S4Sm by looking at the inhibition of growth around a colony of S4Sm. $V$. anguillarum NB10Sm was most sensitive to S4Sm with largest zone of inhibition (ZOI) (diameter $=12.5 \pm 0.5 \mathrm{~mm}) ; \quad R$. crassostreae exhibited slightly less sensitivity to $\mathrm{S} 4 \mathrm{Sm}$ (ZOI $=11.2 \pm 0.3 \mathrm{~mm})$; and the least sensitive pathogen to $\mathrm{S} 4 \mathrm{Sm}$ was $V$. tubiashii $\mathrm{RE} 22 \mathrm{Sm}(\mathrm{ZOI}=9.2 \pm 0.6 \mathrm{~mm})$ (Fig. 1b). These data were consistent with the results for minimum inhibitory concentration (MIC) of TDA against each of the three pathogens: the MIC for TDA against NB10Sm was $1.25 \mu \mathrm{g} / \mathrm{ml}$, against $R$. crassostreae the MIC was $5 \mu \mathrm{g} / \mathrm{ml}$, and against RE22Sm the MIC was $6.25 \mu \mathrm{g} / \mathrm{ml}$.

\section{Biofilm formation by $P$. inhibens S4Sm}

S4Sm formed thick biofilms on glass, as determined using the crystal violet staining assay. The $\mathrm{OD}_{580}$ value for the S4Sm biofilm after $60 \mathrm{~h}$ was $\sim 4.0$ at $27{ }^{\circ} \mathrm{C}$ under 
A

B
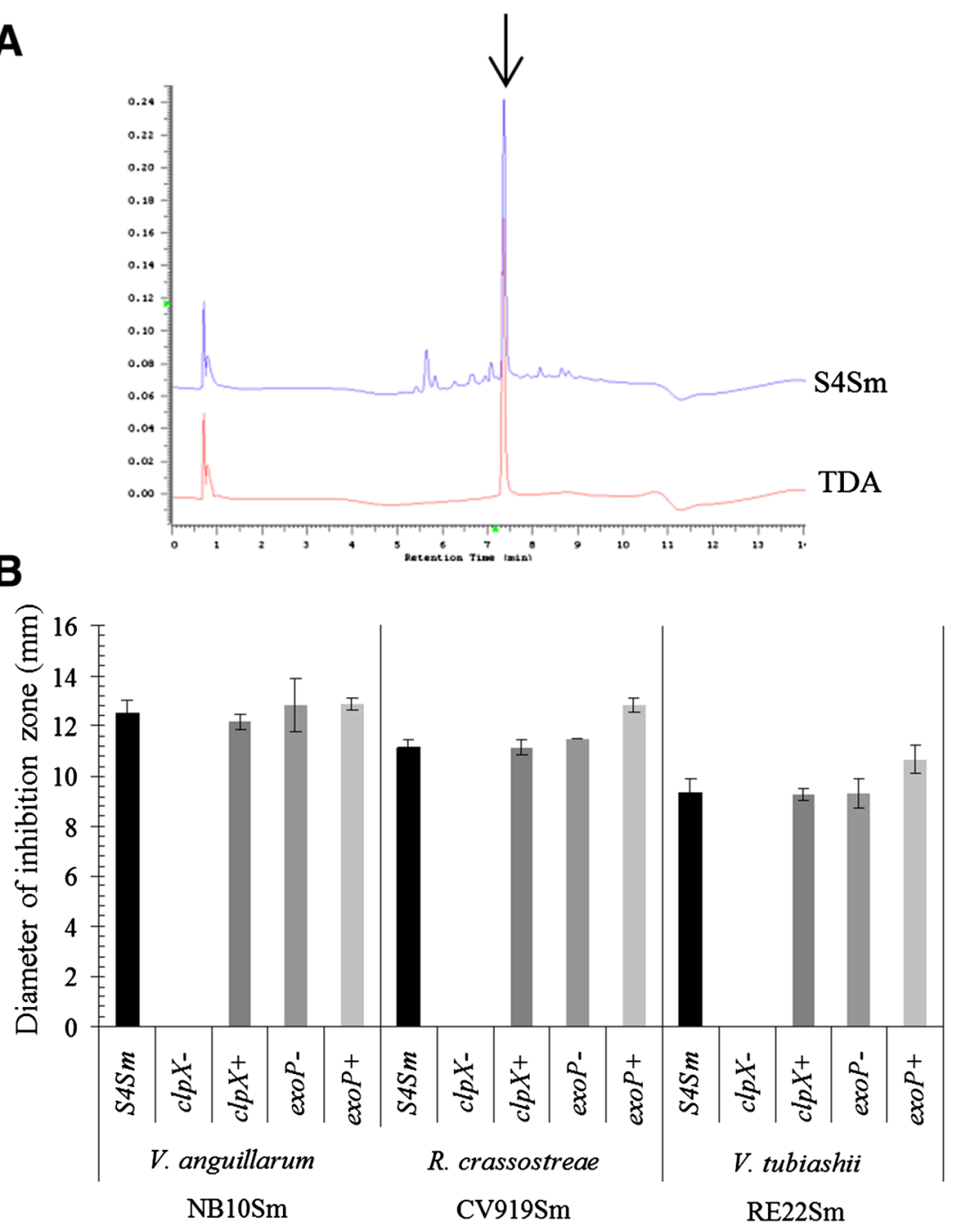

C

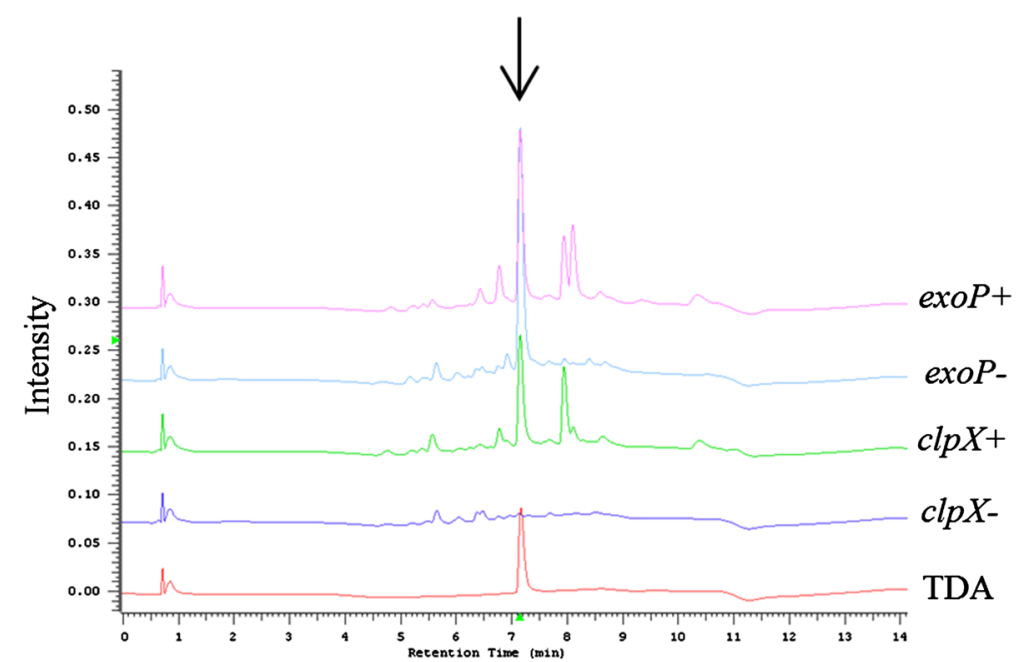

Fig. 1 (See legend on next page.) 
(See figure on previous page.)

Fig. 1 Reversed-phase HPLC chromatograms of ethyl acetate extracts from Phaeobacter strains to detect TDA. a Authentic TDA and extract from wild type strain S4Sm. b Inhibition zone assay of S4Sm, clpX mutant (clpX-), clpX complement (clpX+), exoP mutant (exo -) or exoP complement (exoP+) on YP30 plates coated by V. anguillarum (NB10Sm), V. tubiashii (RE22Sm) or R. crassostreae (CV919Sm) after $24 \mathrm{~h}$ at $27^{\circ} \mathrm{C}$. c Authentic TDA and extracts from $c l p X$ mutant strain ( $c \mid p X-)$, $c l p X$ complement $(c \mid p X+)$, exoP mutant strain (exoP-), exoP complement (exoP+). The data presented are averages of two independent experiments and each independent experiment has three replicates. Error bars represent one

standard deviation

static conditions (Table 1). In contrast, all three marine pathogens ( $V$. anguillarum, $V$. tubiashii, and $R$. crassostreae) used in this study formed biofilms that were between 13.4-14.9 \% of the S4Sm (Table 3) $(P<0.05)$. These data suggested that S4Sm was able to form a thick, dense biofilm matrix on glass coverslips and tubes.

\section{Effect of clpX gene mutation on TDA production}

In order to examine the roles of TDA production and biofilm formation in the probiotic activity of S4, we constructed mutations in the $t d a A, t d a B$, and $t d b D$, genes, previously shown to be part of the TDA biosynthesis pathway [21]. These mutants not only lost TDA production, but also were defective for biofilm formation (Additional file 4). To differentiate the roles of TDA production and biofilm formation in probiotic activity in oysters, we constructed mutants deficient in either TDA synthesis or biofilm production. It was previously shown that mutation in $c l p X$ resulted in the loss of TDA production in Phaeobacter sp. strain 27-4 [21]. The $c l p X$ gene was PCR amplified and sequenced. The derived amino acid sequence was compared (using BLASTx) to other clpX genes already available for Phaeobacter strains in the non-redundant protein GenBank database. The S4Sm ClpX protein has $100 \%$ identity to other $P$. inhibens ClpX proteins. The clpX gene was found to encode a 408 amino acid ATPdependent protease ATP-binding subunit and is part of the ClpXP multimer (Accession number: WP_014874379).

Table 1 Quantification of biofilm formation by measuring optical density at $580 \mathrm{~nm}\left(\mathrm{OD}_{580}\right)$ of crystal violet dye attached to the cells forming biofilms on glass tubes at $27{ }^{\circ} \mathrm{C}$ under static conditions at $60 \mathrm{~h}$

\begin{tabular}{lc}
\hline Strains & $\mathrm{OD}_{580}( \pm \mathrm{SD})^{\mathrm{a}}$ \\
\hline P. inhibens S4Sm & $3.89 \pm 0.06$ \\
P. inhibens WZ10 (clpX-) & $3.90 \pm 0.12$ \\
P. inhibens WZ11 (clpX+) & $4.0 \pm 0.06$ \\
P. inhibens WZ20 (exoP-) & $1.60 \pm 0.09^{\mathrm{b}}$ \\
P. inhibens WZ21 (exoP+) & $3.90 \pm 0.10$ \\
V. anguillarum NB10Sm & $0.58 \pm 0.02^{\mathrm{b}}$ \\
V. tubiashii RE22Sm & $0.54 \pm 0.02^{\mathrm{b}}$ \\
R. crassostreae CV919Sm & $0.52 \pm 0.08^{\mathrm{b}}$ \\
\hline $\begin{array}{l}\text { aBiofilm formation quantified by crystal violet dye assay as described in the } \\
\text { Materials and Methods. The data presented are the average of two } \\
\text { independent experiments, each with three replicates. SD }=\text { standard deviation } \\
\text { bStatistically significant difference }(\mathrm{P}<0.05) \text { compared to S4Sm }\end{array}$
\end{tabular}

Mutation of $c l p X$ by insertional mutagenesis resulted in the loss of TDA production. UHPLC analysis data (Fig. 1c) showed that no TDA was present in $c l p X$ mutant supernatant. Further, there were no inhibition zones around the $c l p X$ mutant cells when tested against the three pathogens, $V$. anguillarum $\mathrm{NB} 10 \mathrm{Sm}, V$. tubiashii $\mathrm{RE} 22 \mathrm{Sm}$, and $R$. crassostreae CV919Sm (Fig. 1b). Additionally, culture supernatant from the $c l p X$ mutant was not able to kill NB10Sm cells (Table 2). Complementation of the $c l p X$ gene restored TDA production (Fig. 1c) and anti-Vibrio activity (Fig. 1b and Table 2). Mutation of $c l p X$ did not result in defective biofilm formation (Table 1). The $c l p X$ mutant and the $c l p X$ complement exhibited the same growth rate and final cell density as the wild type when grown in YP30 under shaking and static conditions (Additional file 5).

\section{Effect of exoP gene mutation on biofilm formation}

In order to develop a strain of S4 defective in biofilm formation but able to produce TDA, the exoP gene, which encodes an exopolysaccharide biosynthesis domain protein (based on Tigrfam classification systems), was identified in $P$. inhibens S4Sm strain. Mutation of exoP resulted in decreased biofilm formation, with the exoP mutant exhibiting only $\sim 40 \%$ of the wild type level of biofilm formation (Table 1) $(\mathrm{P}<0.05)$. Complementation of exoP gene restored biofilm formation to wild type level (Table 1). Mutation of exoP did not result in defective TDA production (Fig. 1b). The exoP mutant and the exoP complement exhibited the same growth rate and

Table 2 Killing ability of culture supernatant of various $P$. inhibens strains against $V$. anguillarum NB10Sm cells ${ }^{a}$

\begin{tabular}{ll}
\hline Treatment & $\begin{array}{l}\text { Sunviving V. anguillarum cell density } \\
(\mathrm{CFU} / \mathrm{ml}) \text { after the treatment }\left( \pm \mathrm{SD}^{\mathrm{b}}\right)\end{array}$ \\
\hline NSS $^{\mathrm{c}}$ (negative control) & $40.7( \pm 3.8) \times 10^{7}$ \\
S4Sm culture supernatant & $<10$ \\
WZ10 (clpX-) culture supernatant & $41.3( \pm 1.5) \times 10^{7}$ \\
WZ11 (clpX+) culture supernatant & $<10$ \\
WZ10 (clpX-) culture supernatant plus TDA & $<10$ \\
WZ20 (exOP-) culture supernatant & $<10$ \\
WZ21 (exOP+) culture supernatant & $<10$ \\
\hline
\end{tabular}

${ }^{\mathrm{a} C u l t u r e}$ supernatant from each strain collected after two-day incubation. The data presented are from a representative experiment of two independent experiments

${ }^{\mathrm{b}} \mathrm{SD}=$ standard deviation

${ }^{\mathrm{c}} \mathrm{NSS}$ : Nine salts solution 
final cell density as the wild type when grown in YP30 under shaking and static conditions (Additional file 5).

Effect of $c l p X$ and exoP mutations on the ability of $P$. inhibens biofilms to antagonize colonization of coverslips by Vibrio species

The $c l p X$ mutant (no TDA production and normal biofilm) and the exoP mutant (normal TDA production and reduced biofilm) allowed us to examine the relative roles of biofilm formation and TDA production on the ability of $24 \mathrm{~h}$ biofilms of S4Sm to: 1) antagonize colonization of glass surfaces by $V$. tubiashii RE22Sm and 2) decrease the cell density $(\mathrm{CFU} / \mathrm{ml})$ of the pathogen in the liquid culture media. When a co-colonized glass coverslip was examined after $72 \mathrm{~h}$ of incubation by laser scanning confocal microscopy, more RE22Sm cell clusters were observed in the biofilm matrix of the $c l p X$ mutant than in the biofilm matrix of either S4Sm wild type or exoP (Fig. 2a). These observations were reflected in the viable cell counts of the $V$. tubiashii RE22Sm in both biofilms (sessile cells; Fig. 2b) and in suspension (planktonic cells; Fig. 2c) when grown in the presence of biofilms of $P$. inhibens S4Sm wild type, the clpX mutant or the exoP mutant. For example, as shown in Fig. $2 b$ at $123 \mathrm{~h}$, the number of viable RE22Sm in the

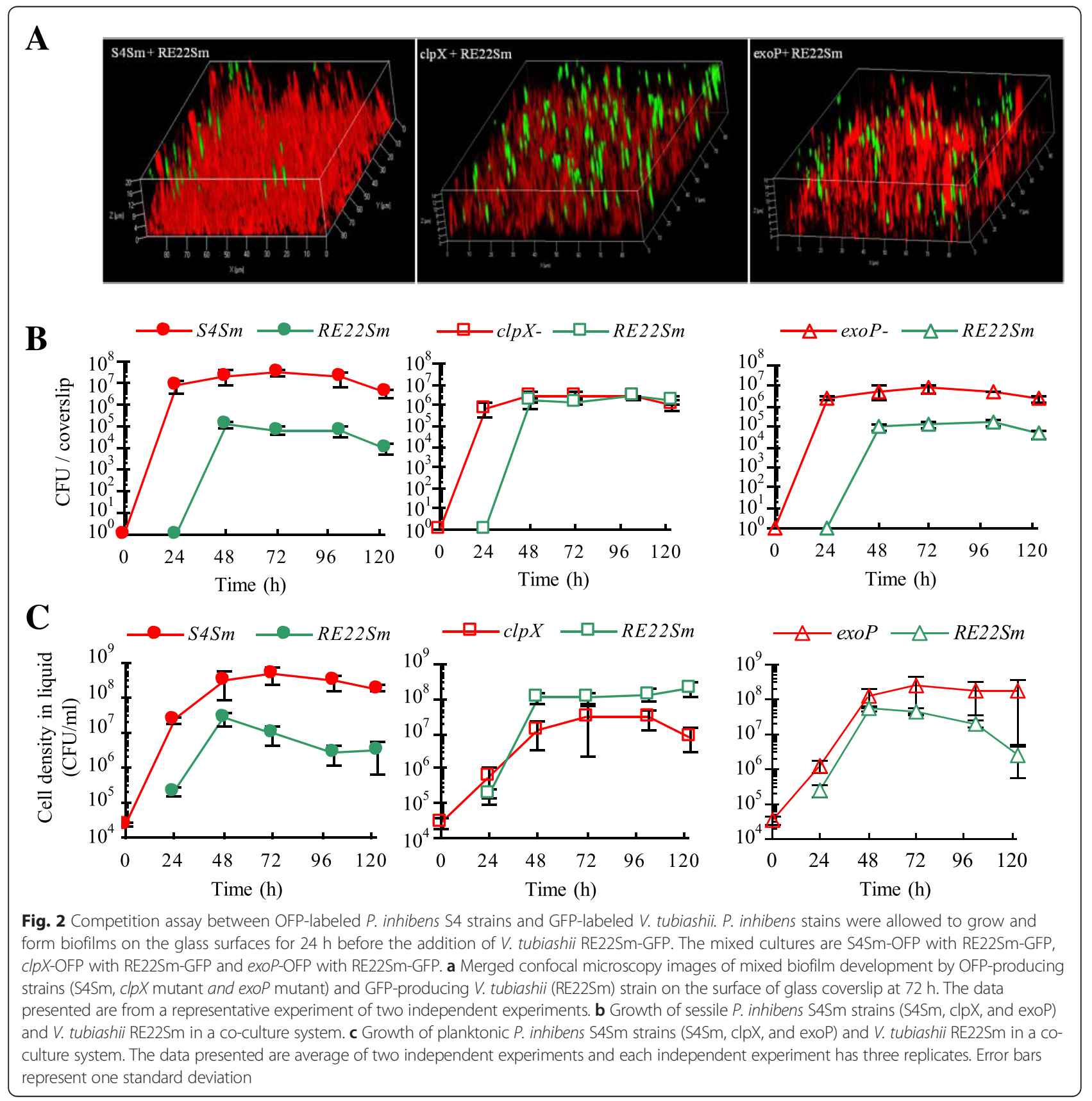


biofilm on a coverslip was $1 \times 10^{4} \mathrm{CFU}$ when precolonized with S4Sm. In contrast, the number of RE22Sm cells increased 180-fold (to $1.8 \times 10^{6} \mathrm{CFU} /$ coverslip) when grown in the presence of the $c l p X$ mutant. This was about the same number of cells on a coverslip as when RE22Sm was allowed to colonize alone $\left(2.0 \times 10^{6} \mathrm{CFU} /\right.$ coverslip $)$. Further, when grown in the presence of the exoP mutant the number of viable RE22Sm cells on the coverslip was 4.5 -fold higher $\left(4.5 \times 10^{4} \mathrm{CFU} /\right.$ coverslip) than in the presence of S4Sm cells $\left(1 \times 10^{4} \mathrm{CFU} /\right.$ coverslip) (Fig. 2b). This is a significant difference in RE22Sm biofilm formation $(\mathrm{P}<0.05)$. In suspension, the cell density of RE22Sm reached $2 \times 10^{8} \mathrm{CFU} / \mathrm{ml}$ under conditions of precolonization by the $\operatorname{clpX}$ mutant; this was similar to the density of RE22Sm grown alone $(1.8 \times$ $\left.10^{8} \mathrm{CFU} / \mathrm{ml}\right)$, but about two orders of magnitude higher than when RE22Sm was co-cultured with either S4Sm $\left(3.1 \times 10^{6} \mathrm{CFU} / \mathrm{ml}\right)$ or exoP $\left(2.6 \times 10^{6} \mathrm{CFU} / \mathrm{ml}\right)$ at $123 \mathrm{~h}$ (Fig. 2c, $\mathrm{P}<0.05$ ). These data showed that the $c l p X$ mutant was not able to inhibit RE22Sm growth or biofilm formation under the tested conditions. While the exoP mutant was able to inhibit RE22Sm biofilm formation to the same extent as the wild type $\mathrm{S} 4 \mathrm{Sm}$, the exoP mutant showed decreased ability to inhibit RE22Sm planktonic growth.

\section{Effects of exogenous TDA on the antagonistic activity of the clpX mutant}

In order to confirm the relationship between the loss of TDA production and the inability of the $\operatorname{clp} X$ mutant biofilm to block colonization by the tested pathogens, exogenous TDA $(10 \mu \mathrm{g} / \mathrm{ml})$ or the same volume of distilled water (no extra TDA added) was added to the co-culture system of the $c l p X$ mutant (TDA deficient) and RE22Sm at the same time as the pathogens. Addition of TDA suppressed biofilm formation (Fig. 3a, by $\sim 10^{2}$ to $10^{3}$ fold) and planktonic growth (Fig. 3c, by $>10^{4}$ fold) by RE22Sm cells for $24 \mathrm{~h}$. This was seen in mixed cultures of RE22Sm plus either S4Sm or the $\operatorname{clpX}$ mutant or in the monoculture of RE22Sm. Further, the number of RE22Sm cells in all three TDA-supplemented cultures, whether as biofilms or planktonic cells, was not statistically different. However, the effects of a single dose of exogenous TDA were transitory. At $48 \mathrm{~h}$, the amount of RE22Sm cells co-cultured with the $c l p X$ mutant and exogenous TDA increased over 160 -fold, and were not significantly different from the values for RE22Sm cultured alone (Fig. 3a and c). The confocal micrographic images of biofilms from $48 \mathrm{~h}$ cultures confirmed that more RE22Sm cells (green) were observed in the $c l p X$ mutant biofilm (with exogenous TDA) than in S4Sm biofilm (Fig. 3b).

\section{Effects of $V$. tubiashii on growth of $P$. inhibens strains in competition assays}

In order to see if $V$. tubiashii would affect the growth of our various $P$. inhibens strains, we compared the growth of $P$. inhibens strains in the presence of $V$. tubiashii with growth in monoculture controls. Growth of wild type S4Sm and the exoP mutant were not affected by $V$. tubiashii on the coverslip (Fig. 4a, left and right panels, respectively) or in suspension (Fig. 4b, left and right panels, respectively). In contrast, the growth of the $\operatorname{clpX}$ mutant was affected by $V$. tubiashii. At each time point tested, the density of the $c l p X$ mutant (grown with RE22Sm) was lower than that of the monoculture control (Fig. 4a \& b, center panels). For example, at $72 \mathrm{~h}$ the biofilm density of $c l p X$ mutant cells grown in the presence of RE22 was $13.2 \%$ of $c l p X$ mutant cells grown axenically $\left(3.3 \times 10^{6} \pm 5.3 \times 10^{5} \mathrm{CFU} /\right.$ coverslip vs. $2.5 \times$ $10^{7} \pm 1.2 \times 10^{6} \mathrm{CFU} /$ coverslip, $\left.\mathrm{P}<0.05\right)$. Similarly, the planktonic cell density of $c l p X$ mutant cells grown in the presence of RE22Sm was $13.5 \%$ of $c l p X$ mutant cells grown axenically $\left(3.1 \times 10^{7} \pm 6.0 \times 10^{6} \mathrm{CFU} / \mathrm{ml}\right.$ vs. $2.3 \times$ $\left.10^{8} \pm 6.9 \times 10^{7} \mathrm{CFU} / \mathrm{ml}, \mathrm{P}<0.05\right)$. Additionally, when $V$. anguillarum NB10Sm was co-cultured with either S4Sm or the exoP mutant, it did not affect their growth; however, NB10Sm did inhibit the growth of the $c l p X$ mutant (Additional file 6).

\section{Effects of co-incubation with Phaeobacter strains on pathogen growth and biofilm formation}

To determine if $P$. inhibens S4Sm can compete against Vibrio pathogens when added at the same time, competition assays were performed (Fig. 5). The amount of RE22Sm cells in the biofilm was $\sim 8.3 \times 10^{7} \mathrm{CFU} /$ coverslip at $48 \mathrm{~h}$ (Fig. 5a). This was 830-fold more RE22 cells than detected in the biofilm which was pre-colonized with $\mathrm{S} 4 \mathrm{Sm}$ for $24 \mathrm{~h}$ $\left(1 \times 10^{4} \mathrm{CFU} /\right.$ coverslip; Fig. $\left.2 \mathrm{~b}\right)$. Similarly, without precolonization by the $P$. inhibens mutants $(\operatorname{clpX}$ or exoP mutants) RE22Sm exhibited 10- to 100-fold more cells in the mixed biofilm compared to biofilms formed with precolonization by the $P$. inhibens mutants (for exoP: the amount of RE22Sm with pre-colonization is $\sim 1 \times 10^{5} \mathrm{CFU} /$ coverslip, without pre-colonization $\sim 1.1 \times 10^{7} \mathrm{CFU} /$ coverslip; for $\operatorname{clpX}$ : with pre-colonization $\sim 1.2 \times 10^{6} \mathrm{CFU} /$ coverslip, without pre-colonization $\sim 1.0 \times 10^{7} \mathrm{CFU} /$ coverslip) (Fig. 2b, Fig. 5a). Further, when S4Sm was added at the same time as the pathogen, cell density of planktonic RE22Sm (at $48 \mathrm{~h}$ ) was $\sim 9.3 \times 10^{8} \mathrm{CFU} / \mathrm{ml}$ (Fig. 5b), more than 30-fold higher than the density of RE22Sm observed in the pre-colonized culture $\left(2.8 \times 10^{7} \mathrm{CFU} / \mathrm{ml}\right)$ (Fig. $\left.2 \mathrm{~d}\right)$. In contrast, pre-colonization with $\mathrm{S} 4 \mathrm{Sm}$ was not necessary to antagonize $V$. anguillarum (NB10Sm). In experiments where S4Sm and NB10Sm were inoculated together, NB10Sm was eliminated from both the coverslip biofilm and the liquid culture by 40 to $48 \mathrm{~h}$ (Additional file 7). Further, the exoP mutant inhibited NB10Sm biofilm formation and growth in suspension almost as well as $\mathrm{S} 4 \mathrm{Sm}$. In contrast, the $c l p X$ mutant (TDA deficient) exhibited almost no inhibition of either biofilm formation or planktonic growth 


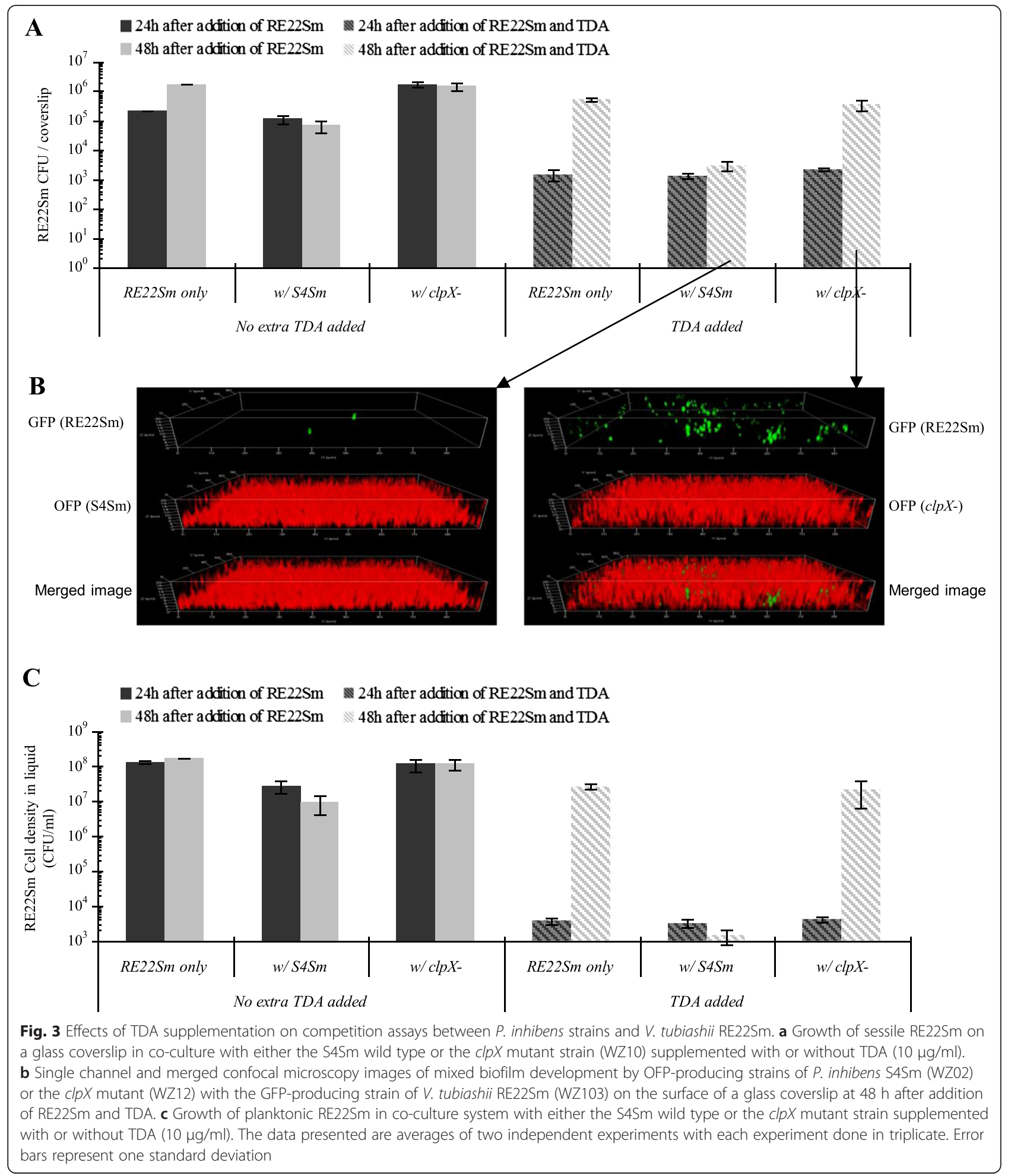

of NB10Sm, compared to NB10Sm grown alone. These observations are also illustrated by the confocal images of biofilms formed by OFP-tagged $P$. inhibens strains and GFPtagged NB10Sm (WZ203) cells (Additional file 7).
Effect of mutations in $c l p X$ and exoP on probiotic activity of $P$. inhibens against $V$. tubiashii in oyster larvae

In order to determine if mutations in TDA production or biofilm formation would affect the probiotic activity 

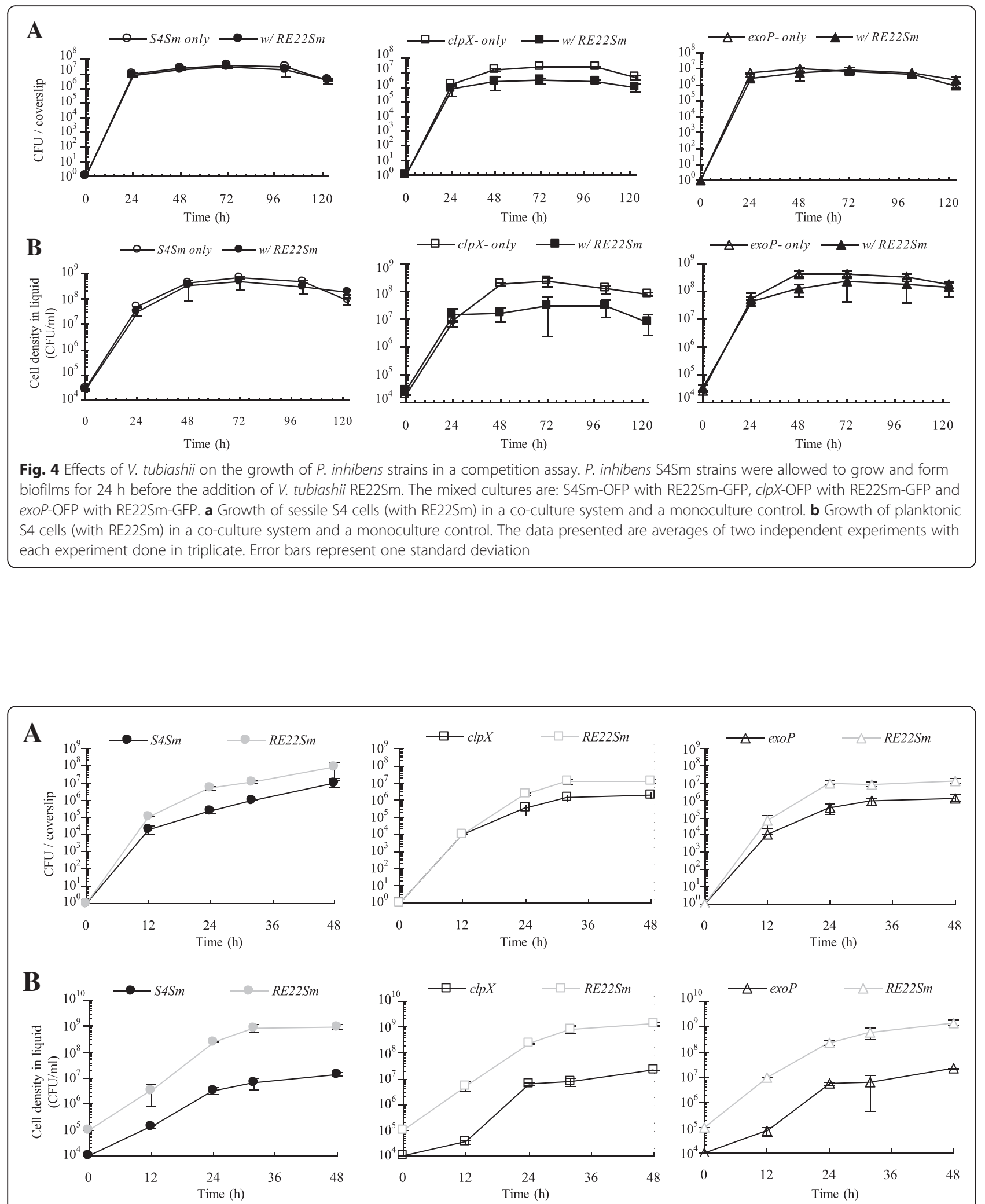

Fig. 5 Competition between $P$. inhibens S4Sm strains and V. tubiashii RE22 without pre-colonization by P. inhibens. The mixed cultures are: S4Sm-OFP with RE22Sm-GFP, clpX-OFP with RE22Sm-GFP, and exoP-OFP with RE22Sm-GFP. a Growth of sessile S4 strains and RE22Sm in a co-culture system. b Growth of planktonic S4 strains and RE22Sm in a co-culture system. The data presented are averages of two independent experiments with each experiment done in triplicate. Error bars represent one standard deviation 
of S4Sm against $V$. tubiashii in vivo, larval oyster challenge assays were performed as described by Karim et al. [16]. $P$. inhibens mutants showed a significant reduction in their ability to protect larval oysters against $V$. tubiashii challenge compared to wild type S4Sm (Fig. 6). The clpX mutant exhibited a $>50 \%$ decline in oyster larvae survival compared to S4Sm (S4Sm: $72.4 \% \pm 1.4 \%$ vs. clpX: $35.7 \% \pm 3.3 \%, \mathrm{P}<$ $0.05)$, while the exoP mutant provided almost $70 \%$ of the protection as $\mathrm{S} 4 \mathrm{Sm}$ (S4Sm: $72.4 \% \pm 1.4 \%$ vs. exoP: $50.6 \% \pm 8.3 \%, \mathrm{P}<0.05$ ) (Fig. 6). Thus, both $P$. inhibens mutants still provided partial protection. Survival in larvae pretreated with either the clpX or exoP mutant $(35.7 \% \pm$ $3.3 \%$ and $50.6 \% \pm 8.3 \%$, respectively) was significantly higher than the survival of larvae treated only with RE22 (20.3 \% $\pm 1.9 \%, \mathrm{P}<0.05)$ (Fig. 6).

\section{Discussion}

Several Phaeobacter species are known to have probiotic activity and are able to protect fish species against bacterial pathogens [11]. The production of the broad-spectrum antibiotic, tropodithietic acid (TDA), is regarded as one of the major factors contributing to probiotic activity against V.anguillarum infection in turbot and cod [11]. We recently reported that the new isolate $P$. inhibens $\mathrm{S} 4 \mathrm{Sm}$ protects the Eastern oyster (Crassostrea virginica) from infection by two oyster pathogens, $V$. tubiashii and $R$. crassostreae [16]. In this report, we dissect the roles of TDA biosynthesis and biofilm formation in promoting probiotic activity by $P$. inhibens $\mathrm{S} 4 \mathrm{Sm}$, showing that both mechanisms are involved.

Although the TDA biosynthetic pathway has not been fully elucidated, many of the genes required for the formation of TDA and much of the pathway have been

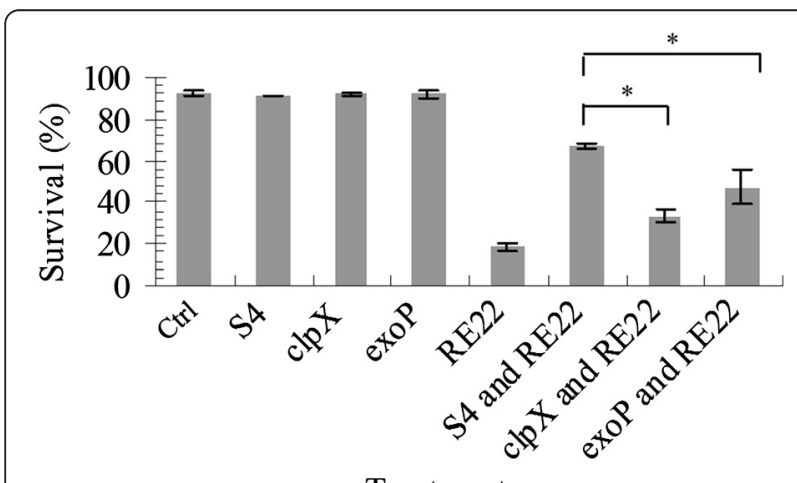

Treatment

Fig. 6 Oyster larvae survival in the presence of $P$. inhibens strains after challenge with $V$. tubiashii. The $P$. inhibens 54 Sm strains $\left(1 \times 10^{4} \mathrm{CFU} / \mathrm{ml}\right)$ were introduced $24 \mathrm{~h}$ before larvae were challenged with $\mathrm{V}$. tubiashii RE22Sm $\left(1 \times 10^{5} \mathrm{CFU} / \mathrm{ml}\right)$. Oyster larvae treated only with artificial seawater served as control (mock). Oyster lanvae survival $(\% \pm \mathrm{SD})$ was determined $24 \mathrm{~h}$ after challenge with RE22Sm Bars marked with an asterisk $\left(^{*}\right)$ show significant differences $(p<0.05)$. Representative of at least 3 experiments. Error bars represent one standard deviation discovered $[21,23,24]$. One gene reported to be involved in TDA biosynthesis is $c l p X$ (encoding ClpX) [21]. ClpX is an AAA + ATPase that functions as an unfoldase chaperon for ClpP (ATP-dependent protease) and with $\mathrm{ClpP}$ forms the multimeric ClpXP protease [25]. An insertional mutation in the $c l p X$ gene specifically blocked the biosynthesis of TDA in S4Sm (Fig. 1a) without affecting biofilm formation (Table 1) or growth (Additional file 4). Further, the effects of mutations to clpX upon cell physiology are subtle and diverse [26-28]. In contrast, mutations in $t d a A, t d a B$, and $t d b D$, all block TDA biosynthesis and also affect biofilm formation in S4Sm. The mechanism by which ClpX affects TDA production is still unknown. Additionally, the reasons why mutations in $t d a A, t d a B$, and $t d b D$ decrease biofilm formation, as well as TDA biosynthesis, are not understood, and are not the focus of this study.

The $\operatorname{clp} X$ TDA deficient mutant was unable to inhibit $V$. tubiashii growth in either liquid or as a biofilm on a glass coverslip (Fig. 2); however, when cultures were supplemented with TDA, the growth of planktonic $V$. tubiashii growth was inhibited (Fig. 3). It is well known that organisms in biofilms are more resistant to antibiotics than when suspended in liquid [29]. This is consistent with our data showing that TDA antibiotic activity was more potent against planktonic RE22 cells than towards RE22 cells living in a biofilm. These data, in which the effect of the wild type was restored by adding TDA to the $\operatorname{clp} X$ antibiotic activity mutant, strongly suggest that the loss of TDA production is responsible for the defect in antagonistic activity in the $c l p X$ mutant. Further, $48 \mathrm{~h}$ after the addition of TDA into the co-culture the inhibitory effect of TDA disappeared, likely due to instability of TDA over time or metabolism by $V$. tubiashii. Except for the loss of TDA synthesis, the $\operatorname{clpX}$ mutant exhibited no other defects in growth or biofilm formation compared to the S4Sm wild type when grown in pure culture (Additional file 5). The results reported here confirm the role of TDA as an antibiotic promoting probiotic activity of Phaeobacter species described previously by D'Alvise et al. [11] in another host-pathogen system. It is interesting to note that the growth of the $c l p X$ mutant is depressed by RE22 (Fig. 2), suggesting that TDA production allows $P$. inhibens to compete with faster growing species for available nutrients.

$P$. inhibens, a member of the abundant marine Roseobacter clade, is known to be an excellent colonizer of environmental surfaces [23]. While no study of the effects of biofilm formation on the probiotic mechanism of Phaeobacter has been reported, it is interesting to note that Prol Garcia et al. (2014) recently reported that biofilm formation is not a prerequisite for TDA formation in P. inhibens. In that study, the authors, using Tn5 transposon mutagenesis, identified 22 TDA-positive mutants with defects in biofilm 
formation. Among classes of genes identified as contributing to biofilm formation were those involved in exopolysaccharide formation. In our study, the exoP gene was identified in S4Sm (using RAST [30]) as an exopolysaccharide biosynthesis gene, which is thought to be involved in biofilm formation. Mutation of exoP resulted in a large decrease in biofilm formation (Table 1), and exhibited no other defects in growth or TDA formation (Fig. 1c and Table 2). Thus, our observations correspond to those reported by Prol Garcia et al. (2014) that biofilm formation is not a prerequisite for TDA production and also that mutation of a gene involved with exopolysaccharide production can affect biofilm formation. While the exoP mutant was modestly defective in its ability to inhibit Vibrio species in competition assays (Figs. 2 \& 5) it did exhibit significantly decreased probiotic activity in the oyster challenge assay against $V$. tubiashii (Fig. 6), these declines were less than those seen in the $c l p X$ mutant. We suggest that while in the in vitro (glass coverslip) model the exoP mutant forms much less biofilm than the wild type, enough TDA accumulates to inhibit RE22 to levels near those caused by wild type cells. However, in the in vivo oyster challenge model, the reduced biofilm of the exoP mutant results in decreased TDA production that is diluted by the larger volumes of the system and the feeding activity of the oyster larvae causing less inhibition of RE22. These data suggest that biofilm formation contributes to the probiotic activity of S4Sm. Biofilms may contribute to probiotic activity in two ways. First, biofilms would allow $P$. inhibens to physically occupy potential sites of colonization and prevent the oyster pathogens from gaining access to the oyster. Second, the formation of an extensive biofilm with cells at high density may induce the production of TDA [31]. A more extensive biofilm would produce more TDA and, therefore, more effectively inhibit the ability of pathogens to infect the oyster host.

As a broad spectrum antibiotic TDA inhibits the growth of several marine pathogens [32]. However, in the ocean environment TDA will be rapidly diluted once it is secreted. We suggest that $P$. inhibens requires both TDA production and biofilm formation for effective probiotic activity. The biofilm matrix creates a microenvironment within which TDA can accumulate to reach concentrations high enough to inhibit pathogens. In the absence of TDA, a $P$. inhibens biofilm does not eliminate pathogens and provides only modest protection against disease. Further, $P$. inhibens growing with a diminished biofilm also exhibits significantly reduced probiotic activity probably due to the decreased mass of cells producing TDA and the increase in available sites for pathogens to colonize. Our data indicate that maximum probiotic activity requires both TDA production and biofilm formation.

Karim et al. [16] reported that oyster larvae were best protected when $P$. inhibens $\mathrm{S} 4 \mathrm{Sm}$ was added $24 \mathrm{~h}$ prior to challenge by either of the two oyster pathogens, $V$. tubiashii and $R$. crassostreae. The data presented in this report is consistent with those previous observations and reveal that pre-colonization of a surface by $\mathrm{S} 4 \mathrm{Sm}$ is more effective than co-incubation at inhibiting $V$. tubiashii RE22 from either colonizing the glass coverslip surface or from growing planktonically (Figs. 2 and 5). One potential reason for this need for a $24 \mathrm{~h}$ pre-treatment is the rapid generation time of Vibrio species in YP30 (at $27^{\circ} \mathrm{C}$, with shaking), which is less than $1 \mathrm{~h}$ ( $V$. tubiashii is $\sim 0.53 \mathrm{~h}, V$. anguillarum is $\sim 0.89 \mathrm{~h}$ ), while the doubling time for P. inhibens S4Sm is $\sim 3.1 \mathrm{~h}$. Successful probiotic activity by $\mathrm{S} 4 \mathrm{Sm}$ may be dependent upon growth rate and having enough TDA producing cells in the biofilm to successfully antagonize and out-compete the oyster pathogens. Interestingly, we show in our study that $V$. anguillarum cells are more sensitive to TDA than are $V$. tubiashii cells, and that, while pre-colonization of surfaces by $\mathrm{S} 4 \mathrm{Sm}$ was required to prevent the colonization of coverslips by $V$. tubiashii, it was not required to prevent the colonization by $V$. anguillarum. Consistent with these observations, D'Alvise et al. [11] showed that it was not necessary for $P$. gallaeciensis to precolonize the wells containing cod larvae in order to antagonize $V$. anguillarum and significantly reduce cod larvae mortalities. Our experiments indicate differences between Vibrio species on how they interact with the $\mathrm{S} 4 \mathrm{Sm}$ probiotic. Interestingly, precolonization with RE22 reduces the ability of S4 and mutants to grow \& colonize glass cover slips and to grow planktonically (Fig. 5), suggesting that RE22 is able to modulate the probiotic activity of S4Sm through negative impacts on the ability to grow and/or colonize surfaces.

\section{Conclusions}

The results presented in this study demonstrate that both TDA production and biofilm formation contribute to the probiotic activity of $P$. inhibens $\mathrm{S} 4 \mathrm{Sm}$. Specifically blocking TDA production by mutation of the $c l p X$ gene resulted in a significant decline in probiotic activity as determined by coverslip colonization assay or by survival of oyster larvae challenged by $V$. tubiashii RE22. While reducing biofilm formation by mutation of the exoP gene also resulted in a significant decline in probiotic activity as determined by survival of oyster larvae challenged by $V$. tubiashii RE22, but only a modest decline as measured by coverslip colonization assay. It is possible that biofilm formation contributes to probiotic activity in two ways: 1 ) occupying potential colonization sites and 2) increasing cell density-dependent induction of TDA biosynthesis. Future investigation will examine these possibilities.

\section{Methods}

TDA purification, identification and detection

TDA was produced and extracted using a modified method of Bruhn et al. [13]. P. inhibens S4Sm was 
cultured in $7 \times 1 \mathrm{~L}$ volumes of YP30 culture medium at $27{ }^{\circ} \mathrm{C}$ with shaking at $175 \mathrm{rpm}$. After $96 \mathrm{~h}$, the cells were pelleted by centrifugation at 10,000 rpm for $10 \mathrm{~min}$. The resulting culture supernatants were acidified to $\mathrm{pH} 3$ with formic acid (FA) and extracted with acidified (0.1 \% FA) ethyl acetate. The organic fraction was concentrated in vacuo to yield $0.673 \mathrm{~g}$ of crude extract. The extract was fractionated using C18 flash chromatography (Redisep Rf high performance gold $30 \mathrm{~g}$ hp combiflash column; linear gradient elution $5 \%-100 \% \mathrm{CH}_{3} \mathrm{OH}$ in $\mathrm{H}_{2} \mathrm{O}, 0.1 \% \mathrm{FA}$, $35 \mathrm{ml} / \mathrm{min}, 45 \mathrm{~min})$. Fractions containing TDA $\left(t_{\mathrm{R}}=\right.$ $15 \mathrm{~min}$ ) were further purified by reversed-phased HPLC (Xterra $5 \mu \mathrm{m} \mathrm{C18} 100 \times 3.0 \mathrm{~mm}$ column, $0.5 \mathrm{ml} / \mathrm{min}, 5 \%$ to $100 \% \mathrm{CH}_{3} \mathrm{OH}$ in $\mathrm{H}_{2} \mathrm{O}$ over $24 \mathrm{~min}$ ). Pure TDA $(10 \mathrm{mg})$ was identified based on comparison of ${ }^{1} \mathrm{H}$ NMR (Varian $500 \mathrm{MHz}$ spectrometer) and mass spectral data in comparison to previously reported values (Additional files 1, 2 and 3) [22]. All assays were conducted with purified TDA from $P$. inhibens S4Sm.

Culture supernatants from $P$. inhibens wild type and mutant strains were analyzed by HPLC for the presence of TDA. P. inhibens strains were cultivated in $50 \mathrm{ml}$ YP30 broth until stationary phase $\left(2 \times 10^{9} \mathrm{CFU} / \mathrm{ml}\right)$. Cells were pelleted by centrifugation $(5000 \times g, 10 \mathrm{~min})$ and extracted as described above. The resulting organic extracts were reconstituted as $10 \mathrm{mg} / \mathrm{ml}$ solutions in methanol. Chromatography was performed on a Hitachi LaChromUltra UHPLC equipped with a Fortis C18 UHPLC Column $(1.7 \mu \mathrm{m}, 2.1$ x $50 \mathrm{~mm})$. Method: $0.25 \mathrm{ml} / \mathrm{min}$ flow rate, $5 \% \mathrm{CH}_{3} \mathrm{OH}$ in $\mathrm{H}_{2} \mathrm{O}$ (both acidified with $0.1 \% \mathrm{FA}$ ) for $1 \mathrm{~min}$, linear gradient to $100 \%$ $\mathrm{CH}_{3} \mathrm{OH}$ over $6.2 \mathrm{~min}, 100 \% \mathrm{CH}_{3} \mathrm{OH}$ for $2 \mathrm{~min}$.

\section{Minimum inhibitory concentrations of TDA against $V$. anguillarum, V. tubiashii, and R. crassostreae}

The minimal inhibitory concentrations (MIC) of TDA against selected marine pathogens were determined using a broth dilution method in microtiter plates [33]. Overnight bacterial cultures were diluted to $10^{5} \mathrm{CFU} / \mathrm{ml}$ in YP30 and treated with serial dilutions of pure TDA. After $24 \mathrm{~h}$ incubation at $27{ }^{\circ} \mathrm{C}$, MICs were determined as the lowest concentration where there was no visible growth. Two independent experiments were done and each independent experiment had three replicates.

\section{Bacterial strains, plasmids, and growth conditions}

All bacterial strains and plasmids used in this report are listed in Table 3. P. inhibens strains were routinely grown in yeast extract $(0.5 \%)$-peptone $(0.1 \%)$ broth plus $3 \%$ sea salts, pH 7.6 (YP30) [16], supplemented with the appropriate antibiotic, in a shaking water bath $(175 \mathrm{rpm})$ at $27^{\circ} \mathrm{C}$. Overnight cultures $\left(2 \times 10^{9} \mathrm{CFU} / \mathrm{ml}\right)$ of $P$. inhibens, grown in YP30, were harvested by centrifugation $(8000 \times g, 2 \mathrm{~min})$ and the pelleted cells were washed twice with nine-salt solution (NSS) [34]. Washed cells were resuspended to appropriate cell densities in experimental media. Cell densities were estimated by optical density at $600 \mathrm{~nm}\left(\mathrm{OD}_{600}\right)$ and more accurately determined by serial dilution and spot plating. Specific conditions for each experiment are described in the text. Escherichia coli strains were routinely grown in LuriaBertani broth plus $1 \% \mathrm{NaCl}$ (LB10) [35]. Vibrio anguillarum strains were routinely grown in LB20 at $27{ }^{\circ} \mathrm{C}$ [36]. V. tubiashii and $R$. crassostreae strains were routinely grown in YP30 at $27{ }^{\circ} \mathrm{C}$ [16]. Antibiotics were used at the following concentrations: streptomycin, $200 \mu \mathrm{g} / \mathrm{ml}\left(\mathrm{Sm}^{200}\right)$; ampicillin, $100 \mu \mathrm{g} / \mathrm{ml}\left(\mathrm{Ap}^{100}\right)$ for E. coli and Vibrio strains; chloramphenicol, $20 \mu \mathrm{g} / \mathrm{ml}\left(\mathrm{Cm}^{20}\right)$ for E. coli and $5 \mu \mathrm{g} / \mathrm{ml}$ $\left(\mathrm{Cm}^{5}\right)$ for P. inhibens and Vibrio strains; kanamycin, $50 \mu \mathrm{g} /$ $\mathrm{ml}\left(\mathrm{Km}^{50}\right)$ for E. coli strains and $200 \mu \mathrm{g} / \mathrm{ml}\left(\mathrm{Km}^{200}\right)$ for $P$. inhibens; and tetracycline, $15 \mu \mathrm{g} / \mathrm{ml}\left(\mathrm{Tc}^{15}\right)$ for E. coli and $1 \mu \mathrm{g} / \mathrm{ml}\left(\mathrm{Tc}^{1}\right)$ for $V$. anguillarum. Frozen stocks in glycerol were maintained at $-74{ }^{\circ} \mathrm{C}$ and cultures were routinely identified by phenotypic and genotypic characteristics.

\section{Insertional mutagenesis}

Insertional mutagenesis by homologous recombination was used to create interruptions within specific genes using a modification of the procedure described by Milton and Wolf-Watz [37, 38]. Primers (Table 4) were designed to amplify specific Phaeobacter genes based on homologous sequences from $P$. inhibens 2.10 (GenBank accession No.CP002972.1) (Phaeobacter 2.10 was reclassified into P. inhibens from P. gallaeciensis in 2013 [39]). A fragment of the selected gene was PCR amplified, then digested with SacI and XbaI restriction enzymes, and the DNA fragments separated on a $1 \%$ agarose gel. The gelpurified PCR fragment was ligated into the suicide vector pNQ705 after digestion with SacI and XbaI and the ligation mixture was introduced into E. coli $\mathrm{Sm} 10$ ( $\lambda$ pir) by electroporation $(0.2 \mathrm{~cm}$ cuvette, $2.5 \mathrm{kV}, 200 \Omega, 25 \mu \mathrm{F})$ with Bio-Rad Gene Pulser II. Recombinant plasmids were confirmed by both PCR amplification and sequencing. The mobilizable suicide vector was transferred from $E$. coli $\mathrm{Sm10}(\lambda$ pir) into $\mathrm{S} 4 \mathrm{Sm}$ by conjugation. Transconjugants were selected by utilizing the chloramphenicol resistance gene located on the suicide plasmid. The incorporation of the suicide vector into the gene of interest was confirmed by PCR analysis and DNA sequencing of the mutated genes [37].

\section{Complementation of mutants}

$P$. inhibens mutants were complemented by cloning the target gene fragment into the shuttle vector pBBR1MCS4 (GenBank accession No. U25060), using a modification of the method by Rock and Nelson [40]. Primers (Table 4) were designed with a SacI or $\mathrm{XbaI}$ site added to the $5^{\prime}$ end of the appropriate primer. The primer pair was used to 
Table 3 Bacterial strains and plasmids used in this study

\begin{tabular}{|c|c|c|c|}
\hline Strains or plasmids & Description & Resistance & Reference \\
\hline \multicolumn{4}{|l|}{ P. inhibens } \\
\hline S4 & Previously Phaeobacter sp. S4; wild type isolate from the inner shell of oysters & & Karim et al., 2013 \\
\hline S4Sm & Spontaneous $\mathrm{Sm}^{r}$ mutant of $\mathrm{S} 4$ & $S m^{r}$ & this study \\
\hline WZ10 & clpX insertional mutant of S4Sm & $\mathrm{Sm}^{\mathrm{r}} \mathrm{Cm}^{\mathrm{r}}$ & this study \\
\hline WZ11 & $c l p X+, c l p X$ in trans complement of WZ10 & $\mathrm{Sm}^{r} \mathrm{Cm}^{r} \mathrm{Ap}{ }^{r}$ & this study \\
\hline WZ20 & exoP insertional mutant of $\mathrm{S} 4 \mathrm{Sm}$ & $\mathrm{Sm}^{\mathrm{r}} \mathrm{Cm}^{\mathrm{r}}$ & this study \\
\hline WZ21 & exoP+, exoP in trans complement of WZ20 & $S m^{r} \mathrm{Cm}^{r} \mathrm{Ap}{ }^{r}$ & this study \\
\hline WZ02 & S4Sm (pRhokHi-2-ofp) & $\mathrm{Sm}^{\mathrm{r}} \mathrm{Cm}^{\mathrm{r}} \mathrm{Km}^{\mathrm{r}}$ & this study \\
\hline WZ12 & clpX, WZ10 (pRhokHi-2-ofp) & $\mathrm{Sm}^{r} \mathrm{Cm}^{r} \mathrm{Km}^{r}$ & this study \\
\hline WZ22 & exoP, WZ20 (pRhokHi-2-ofp) & $\mathrm{Sm}^{r} \mathrm{Cm}^{r} \mathrm{Km}^{r}$ & this study \\
\hline \multicolumn{4}{|l|}{ V. tubiashii } \\
\hline RE22 & Wild type isolate from oyster larvae & & Estes et al., 2004 \\
\hline RE22Sm & Spontaneous $\mathrm{Sm}^{\mathrm{r}}$ mutant of RE22 & $S m^{r}$ & this study \\
\hline WZ103 & RE22Sm (pRhokHi-2-gfp) & $S m^{r} A p^{r}$ & this study \\
\hline \multicolumn{4}{|l|}{ V. anguillarum } \\
\hline NB10 & Wild type, serotype O1, clinical isolate from the Gulf of Bothnia & & Norqvist et al., 1989 \\
\hline NB10Sm & Spontaneous Sm ${ }^{r}$ mutant of NB10 & $S m^{r}$ & this study \\
\hline WZ203 & NB10Sm (pSUP202P-PflaB-gfp) & $\mathrm{Sm}^{r} \mathrm{Ap}{ }^{r} \mathrm{Tet}^{\mathrm{r}}$ & this study \\
\hline \multicolumn{4}{|l|}{ R. crassostreae } \\
\hline CV919-312 & Wild type isolate from a JOD-affected oyster & & Boettcher et al., 1999 \\
\hline CV919Sm & Spontaneous Smr mutant of CV919-312 T & $S m^{r}$ & this study \\
\hline \multicolumn{4}{|l|}{ E. coli } \\
\hline Sm10 & thi thr leu tonA lacY supE recA RP4-2 Tc::Mu::Km ( $\lambda$ pir) & $\mathrm{Km}^{\mathrm{r}}$ & Simon et al., 1983 \\
\hline S100 & Sm10 harboring pNQ705-1 & & this study \\
\hline WQ10 & Sm10 harboring pNQ705-clpX & & this study \\
\hline WQ20 & Sm10 harboring pNQ705-exoP & & this study \\
\hline WB01 & Sm10 harboring pBBR1MCS4 & & this study \\
\hline WB11 & Sm10 harboring pBBR1MCS4-clpX & & this study \\
\hline WB21 & Sm10 harboring pBBR1MCS4-exoP & & this study \\
\hline S122 & Sm10 harboring pSUP202P-gfp(ORF) & & this study \\
\hline S136 & Sm10 harboring pSUP202P-PflaB-gfp & & this study \\
\hline W900 & Sm10 harboring pRhokHi-2-FbFP & & this study \\
\hline WR03 & Sm10 harboring pRhokHi-2-gfp & & this study \\
\hline WR02 & Sm10 harboring pRhokHi-2-ofp & & this study \\
\hline W901 & Sm10 harboring pmOrange & & this study \\
\hline \multicolumn{4}{|l|}{ Plasmids } \\
\hline pNQ705-1 & $\mathrm{Cm}^{r}$; suicide vector with R6K origin & & Mcgee, 1996 \\
\hline pNQ705-clpX & $\mathrm{Cm}^{r}$; derivative from $\mathrm{pNQ}$ 705-1 for $\mathrm{clpX}$ insertional mutant & & this study \\
\hline pNQ705-exoP & $\mathrm{Cm}^{r}$; derivative from pNQ705-1 for exoP insertional mutant & & this study \\
\hline pBBR1MCS4 & $A p^{r}$; derivative from pBBR1MCS (a broad-host-range cloning vector) & & Kovach et al., 1995 \\
\hline pBBR1MCS4-CIpX & Apr; derivative from pBBR1MCS4 for $\mathrm{clpX}$ in trans complement & & this study \\
\hline pBBR1MCS4-exoP & Apr; derivative from pBBR1MCS4 for exoP in trans complement & & this study \\
\hline pBS(gfp)-Pcampy & Template for gfp ORF PCR amplification & & Eggers et al., 2004 \\
\hline pCE320(gfp)-PflaB & Template for PflaB PCR amplification & & Eggers et al., 2004 \\
\hline
\end{tabular}


Table 3 Bacterial strains and plasmids used in this study (Continued)

\begin{tabular}{|c|c|c|}
\hline pSUP202P & $\mathrm{Ap}^{r} \mathrm{Cm}^{r} \mathrm{~T} c^{r}$; broad host shuttle vector & Simon et al., 1983 \\
\hline pSUP202P-gfp(ORF) & $A p^{r} T c^{r}$; derivative from pSUP202 for GFP tagging & this study \\
\hline pSUP202P-PflaB-gfp & $A p^{r} T C^{r}$; derivative from pSUP202 for GFP tagging & this study \\
\hline pRhokHi-2-FbFP & $\begin{array}{l}\mathrm{Cm}^{r} \mathrm{Km}^{\mathrm{r}} \text {; derivative from pBBR1MCS (a broad-host-range cloning vector) } \\
\text { with promoter Paphll }\end{array}$ & Piekarski et al., 2009 \\
\hline pRhokHi-2-gfp & $\mathrm{Cm}^{\mathrm{r}} \mathrm{Km}^{\mathrm{r}}$; derivative from pRhokHi-2-FbFP with gfp under the control of Paphll & this study \\
\hline pmOrange & Template for ofp ORF PCR amplification & Clontech Laboratories, Inc. \\
\hline pRhokHi-2-ofp & $\mathrm{Cm}^{r} \mathrm{Km}^{r}$; derivative from pRhokHi-2-FbFP with ofp under the control of Paphll & this study \\
\hline
\end{tabular}

amplify the entire gene plus $\sim 500$ bp of the $5^{\prime}$ and $3^{\prime}$ flanking regions from genomic DNA sequences of $P$. inhibens 2.10 (GenBank accession No.CP002972.1). The resulting amplicon was ligated into the pBBR1MCS4 plasmid after digestion with SacI and XbaI and the ligation mixture introduced into $E$. coli $\operatorname{Sm} 10$ ( $\lambda$ pir) by electroporation with Bio-Rad Gene Pulser II. Transformants were selected on LB10-Amp100 agar plates and the recombinant plasmids confirmed by both PCR amplification and sequencing. The complementing plasmid, pBBR1MCS4clpX or pBBR1MCS4-exoP, was transferred from E. coli Sm10 into $c l p X$ or exoP mutants by conjugation using the procedures described previously $[37,41]$. The transconjugants were confirmed by PCR amplification.

\section{Fluorescence tagging of $P$. inhibens strains and Vibrio species}

$P$. inhibens strains were tagged by pRhokHi-2-OFP and $V$. tubiashii was tagged by pRhokHi-2-GFP. The orange fluorescence protein gene ( $o f p)$ and the green fluorescence protein gene $(g f p)$ were PCR amplified by using the appropriate primer pair (Table 4) designed according to the sequence of pmOrange vector (Clontech) and pSUP202p/ PflaB-gfp vector. The PCR product was digested with NdeI and BamHI restriction enzymes and the DNA fragments separated on a $1 \%$ agarose gel. Subsequently, the gel-purified $o f p$ or $g f p$ PCR fragment was ligated into pRhokHi-2 after digestion with NdeI and BamHI and the ligation mixture was introduced into E. coli Sm10 ( $\lambda$ pir)

Table 4 Primers used in this study

\begin{tabular}{|c|c|c|}
\hline Primer & Sequence ( $5^{\prime}$ to $3^{\prime}$, underlined sequences are engineered restriction sites) & Description \\
\hline pw30 & GTATTAGAGCTCATCGCACTGCTTCTTGAGGT & For tdaA insertional mutation, forward, with Sacl site \\
\hline pw31 & CGACTATCTAGAGATGATTGGGTCCTITGCAC & For $t d a A$ insertional mutation, reverse, with $X b a l$ site \\
\hline pw32 & GTATTAGAGCTCAGCAGCCATGAATAGCCTGT & For $t d a B$ insertional mutation, forward, with Sacl site \\
\hline pw33 & CGACTATCTAGAGGGTATCGGATTTCGGATTT & For $t d a B$ insertional mutation, reverse, with $X b a l$ site \\
\hline pw36 & GTATTAGAGCTCATCTTTGGCTCCATCGACAT & For $t d b D$ insertional mutation, forward, with Sacl site \\
\hline pw37 & CGACTATCTAGAGCACATTGTTGGGAAACTGA & For $t d b D$ insertional mutation, reverse, with $X b a l$ site \\
\hline pw108 & GAAGAGCTCGGACGACTATGTGATTGGTCAGGC & For clpX insertional mutation, forward, with Sacl site \\
\hline pw109 & GGGTCTAGACGACGTTATATTCCGACGCCTGCA & For $c l p X$ insertional mutation, reverse, with Xbal site \\
\hline pw153 & GTATTAGAGCTCGAGCATAACCGCTTTGCCCGCCGCCCA & For exoP insertional mutation, forward, with Sacl site \\
\hline pw154 & CGACTATCTAGACCATGCTGAGTGCAAGGTTGACGGCGG & For exo $P$ insertional mutation, reverse, with $X b a l$ site \\
\hline pw127 & GCATTAGAGCTCGTCAGATTGGCCGAAGCCCCTTIT & For clpX in trans complement, forward, with Sacl site \\
\hline pw128 & CGGCTATCTAGACGAACTCACCACCTGAGGAGATACGT & For $c \mid p X$ in trans complement, reverse, with Xbal site \\
\hline pw166 & GTATTAGAGCTCCCCGTCCGATGTGTCAAAATAGGT & For exoP in trans complement, forward, with Sacl site \\
\hline pw165 & CGTCTICTAGAGGTGCCTGCGGTCATCACCATGAC & For exoP in trans complement, reverse, with $X b a l$ site \\
\hline pwGFP-F & GCGGTACATATGTAAGGAGGAAAAACATATG & For amplification of gfp ORF, forward, with Ndel site \\
\hline pWGFP-R & CTATATGGATCCCAGATCTATTTGTATAGTTCATCCA & For amplification of gfp ORF, reverse, with BamHI site \\
\hline Pm113 & GGTACCTGTCTGTCGCCTCTTGT & For amplification of PflaB, forward, with Kpnl site \\
\hline $\operatorname{Pm} 114$ & GGTACCATATCATTCCTCCATGAT & For amplification of PflaB, forward, with Kpnl site \\
\hline pwmO-F & GCGGTACATATGATGGTGAGCAAGGGCGAGGAGAAT & For amplification of ofp ORF, forward, with Ndel site \\
\hline pwmO-R & CTATATGGATCCCTTGTACAGCTCGTCCATGCCGCC & For amplification of ofp ORF, reverse, with BamHI site \\
\hline
\end{tabular}


by electroporation with Bio-Rad Gene Pulser II. Transformants were selected on LB10- $\mathrm{Cm}^{20}$ agar plates. All plasmids were transferred from E. coli SM10 to recipient strains of $P$. inhibens $\mathrm{S} 4 \mathrm{Sm}, V$. tubiashii RE22Sm, $R$. crassostreae CV919Sm, and $V$. anguillarum NB10Sm using the method described previously by Mou et al. [41]. The transconjugants were confirmed by fluorescence microscopy.

\section{Biofilm formation}

Biofilm formation was assessed using a modification of the crystal violet $(\mathrm{CV})$ staining method [19]. Bacteria were grown for 2 days in YP30 $\left(27^{\circ} \mathrm{C}\right.$ with shaking) to stationary phase $\left(2 \times 10^{9} \mathrm{CFU} / \mathrm{ml}\right)$. Cells $(2 \mu \mathrm{l})$ were transferred into $2 \mathrm{ml}$ of fresh YP30 broth in $30 \mathrm{~mm} \times$ $100 \mathrm{~mm}$ borosilicate (Pyrex) glass culture tubes containing $2 \mathrm{ml} \mathrm{YP30} \mathrm{broth} \mathrm{and} \mathrm{allowed} \mathrm{to} \mathrm{grow} \mathrm{at} 27^{\circ} \mathrm{C}$ without shaking. When sampling, the liquid culture was discarded and each tube rinsed twice with NSS to remove loosely attached cells. The biofilm attached to the test tube wall was stained with $2 \mathrm{ml}$ of $\mathrm{CV}$ solution $(0.2 \%)$ for $20 \mathrm{~min}$ at room temperature. Unbound dye was removed with two washes of NSS. The bound dye was eluted with $95 \%$ (vol/vol) ethanol for $30 \mathrm{~min}$ and then the amount of eluted crystal violet was measured by spectroscopy at $580 \mathrm{~nm}$ using a VERSA-MAX microplate reader.

\section{Inhibition zone assay}

Anti-bacterial activity of $P$. inhibens strains was measured by a growth inhibition assay using $V$. anguillarum, $V$. tubiashii, and $R$. crassostreae as the target organisms. An aliquot $(100 \mu \mathrm{l})$ from a stationary phase overnight culture of the appropriate Vibrio or $R$. crassostreae culture $\left(2 \times 10^{9} \mathrm{CFU} / \mathrm{ml}\right)$ was spread onto YP30 agar plates, then $10 \mu \mathrm{l}$ of a 2 -day-old culture $\left(2 \times 10^{9} \mathrm{CFU} / \mathrm{ml}\right)$ of a $P$. inhibens strain was spotted in triplicate onto the pathogen cell lawn. After incubation at $27{ }^{\circ} \mathrm{C}$ for $24 \mathrm{~h}$, the level of antibacterial activity was determined by the diameter of the inhibition zone around the $P$. inhibens colonies.

\section{P. inhibens culture supernatant killing assay}

In order to determine the bactericidal activity of culture supernatants, $P$. inhibens strains were grown for 2 days in YP30 $\left(27^{\circ} \mathrm{C}\right.$ with shaking). Cultures were centrifuged $(8000 \times g, 10 \mathrm{~min})$ and filtered through $0.2 \mu \mathrm{m}$ pore membrane filters to collect filter sterilized cell-free supernatants. Overnight cultures of $V$. anguillarum (NB10Sm) cells $\left(2 \times 10^{9} \mathrm{CFU} / \mathrm{ml}\right)$ were then serially diluted in filter sterilized, cell-free $P$. inhibens culture supernatant obtained from the various strains of $P$. inhibens or NSS, and then spotted (10 $\mu \mathrm{l} /$ spot of diluted $V$. anguillarum cells) in triplicate onto YP30 plates. All experiments were repeated twice. Killing percentage was calculated as follows:
Killing $\%=[($ no. of colonies in NSS control) - (no. of colonies in S4 supernatant treated)/(no. of colonies in NSS control)] $\times 100$.

\section{Glass coverslip colonization competition assay between $P$. inhibens strains and V. tubiashii WZ103 or V. anguillarum WZ203}

This assay was performed using a modification of establishment and invasion of pre-established biofilms method [42]. For all competition experiments, $P$. inhibens strains (S4Sm, clpX mutant and exoP mutant) were grown for 2 days in YP30 $\left(27^{\circ} \mathrm{C}\right.$ with shaking) to stationary phase. Cells were harvested by centrifugation, washed twice in NSS, resuspended in fresh YP30, and then transferred into 6-well plates (Costar, Tewksbury MA). Each well contained a glass coverslip, $4 \mathrm{ml}$ YP30 broth supplemented with streptomycin, and was inoculated with the appropriate $P$. inhibens strain (WZ02, WZ12, or WZ22) tagged with orange fluorescence protein (OFP) (final concentration $\left.\sim 1 \times 10^{4} \mathrm{CFU} / \mathrm{ml}\right)$. For experiments examining the effects of pretreatment with $P$. inhibens, after $24 \mathrm{~h}$ incubation at $27{ }^{\circ} \mathrm{C}$ with no shaking (pretreatment with $P$. inhibens) all coverslips were washed twice with NSS. Each coverslip was transferred into a fresh well containing $4 \mathrm{ml}$ of YP30 broth supplemented with streptomycin plus the green fluorescence protein (GFP)-tagged $V$. tubiashii WZ103 or GFP-tagged $V$. anguillarum WZ203 (final concentration $\sim 1 \times 10^{5} \mathrm{CFU} / \mathrm{ml}$ ). After another $24 \mathrm{~h}$ incubation at $27^{\circ} \mathrm{C}$ with no shaking, all coverslips were removed, washed twice on a rotary shaker (LAB-LINE instrument, Inc.) for 2 min (200 rpm) with NSS, and then transferred into clean wells with fresh YP30 broth and allowed to incubate as before. Two coverslips were removed at each sampling time $(24,48,72 \mathrm{~h})$. One was used for determination of the cell density of the strains on the coverslip; the second one was used for confocal imaging. Glass coverslips were washed with NSS twice on a rotary shaker for 2 min. After draining excess water, coverslips used for confocal imaging were placed on depression slides and cells on the upside of coverslip were wiped off with Kimwipes $^{\mathrm{nt}}$. Coverslips used for CFU determinations were immersed in $50 \mathrm{ml}$ plastic tubes containing $10 \mathrm{ml}$ NSS and glass beads $(0.5 \mathrm{~g}, 1 \mathrm{~mm})$, then vortexed for $1 \mathrm{~min}$. Cell densities $(\mathrm{CFU} / \mathrm{ml})$ in the wells or suspended from the coverslip were determined by serial dilution and spot plating. Appropriate antibiotics were used for selection of bacteria (see Table 3 for antibiotic resistances for each strain). For experiments without pretreatment with $P$. inhibens, all procedures were identical to those described above except that GFP-tagged $V$. tubiashii WZ103 or $V$. anguillarum WZ203 were added at the same time as OFP-tagged $P$. inhibens. In the $V$. anguillarum competition experiments, both $P$. inhibens and $V$. anguillarum were inoculated at $\sim 10^{6} \mathrm{CFU} / \mathrm{ml}$. 
Effects of TDA supplementation on pathogen growth in a co-culture system containing the clpX mutant and a Vibrio species

OFP-tagged $P$. inhibens strains (S4Sm, clpX mutant) grown for 2 days in YP30 $\left(27{ }^{\circ} \mathrm{C}\right.$ with shaking) to stationary phase, cells were transferred into 6-well plates. Each well was inoculated with the appropriate OFPtagged $P$. inhibens strain (initial concentration at $~$ $10^{4} \mathrm{CFU} / \mathrm{ml}$ ) in $4 \mathrm{ml}$ of YP30 broth supplemented with the appropriate antibiotic and one glass coverslip. After $24 \mathrm{~h}$ incubation (pre-treatment with $P$. inhibens), all coverslips were washed twice in NSS. Each coverslip was transferred into a clean well containing $4 \mathrm{ml}$ YP30 broth and either GFP-tagged $V$. anguillarum WZ203 or $V$. tubiashii WZ103 at a concentration of $\sim 10^{5} \mathrm{CFU} / \mathrm{ml}$ plus TDA $(5 \mu \mathrm{g} / \mathrm{ml}$ for $V$. anguillarum WZ203 or $10 \mu \mathrm{g} / \mathrm{ml}$ for $V$. tubiashii WZ103; based on calculated MIC). The biofilms on the coverslips were imaged as described below and cell densities were determined as described above.

\section{Laser confocal scanning microscopy}

Laser confocal scanning microscopy was performed in the Rhode Island Genomic Sequencing Center using a Zeiss Axiolmager 2 microscope equipped for digital image acquisition with a Zeiss AxioCam HRc high-resolution camera and for laser scanning microscopy with a Zeiss LSM 700 confocal module. The confocal module is equipped with four diode lasers with excitation lines at 405, 488, 555, and $639 \mathrm{~nm}$ and utilizes the Zeiss ZEN 2011 software.

\section{Challenge trials}

Oyster larvae $(\mathrm{n}=21-28$ per well, veliger stage, $\sim 0.060-$ $0.150 \mathrm{~mm}$ in diameter) were placed in wells of a 6 -well plate containing $5 \mathrm{ml}$ of sterile filtered seawater (28 psu). Overnight cultures of $P$. inhibens strains grown in YP30 $\left(\sim 10^{9} \mathrm{CFU} / \mathrm{ml}\right)$ were added to a final concentration of $\sim 10^{4} \mathrm{CFU} / \mathrm{ml}$. Plates were incubated at $20{ }^{\circ} \mathrm{C}$ for $24 \mathrm{~h}$ with shaking. Water was changed and $V$. tubiashii RE22 was added at a concentration of $\sim 10^{5} \mathrm{CFU} / \mathrm{ml}$ in seawater and incubated for an additional $24 \mathrm{~h}$ before counting living and dead oysters. Oyster larvae treated only by artificial seawater served as control. The survival rate was calculated by using the formula: Survival rate $(\%)=100 \times$ (number of live larvae/total number of larvae). These experiments were run at least 2 times in triplicate [16]. As invertebrates, oysters are exempt from approval from the University of Rhode Island Institutional Animal Care and Use Committee.

\section{Statistical analysis}

Data are expressed as means \pm standard deviation (SD). Two-tailed, unpaired Student's $t$ tests were used for statistical analyses for all experiments, and $P$ values of $<0.05$ were considered statistically significant.

\section{Additional files}

\begin{abstract}
Additional file 1: A) Electrospray ionization MS of purified TDA, structure shown on right, in the positive ion mode. The spectrum shows expected losses of $\mathrm{H} 2 \mathrm{O}$ and $\mathrm{CO} 2 \mathrm{H}$. (PDF $64 \mathrm{~kb}$ )
\end{abstract}

Additional file 2: 1H NMR spectrum (500 MHz, C6D6) for purified TDA. The spectrum is expanded to show the aromatic region of interest. Spectrum was referenced to residual benzene resonance at $7.16 \mathrm{ppm}$. (PDF $110 \mathrm{~kb}$ )

Additional file 3: 1H NMR spectroscopic data of purified TDA from P. inhibens. Comparison is provided to data published by Liang (2003). (PDF $7 \mathrm{~kb}$ )

Additional file 4: A) Reversed-phase HPLC chromatograms of ethyl acetate extracts from Phaeobacter S4 mutant strains. B) Quantification of biofilm formation by measuring OD580 of crystal violet dye attached to the cells forming biofilms on glass tubes at $27^{\circ} \mathrm{C}$ under static condition. The data presented are average of two independent experiments and each independent experiment has three replicates. Error bars represent one standard deviation. (PDF $83 \mathrm{~kb}$ )

Additional file 5: Growth curve of Phaeobacter S4 strains under different conditions (static vs. shaking). Overnight culture of Phaeobacter cells were grown in YP30 media and then back-diluted into fresh YP30 1:1000 dilution. Samples were taken at the indicated times and OD600 value were measured by a spectroscopy. Error bars represent one standard deviation. (PDF $340 \mathrm{~kb}$ )

Additional file 6: Effects of $V$. anguillarum NB10 on the growth of $P$. inhibens strains in a competition assay without pre-colonization by $P$. inhibens. The mixed cultures are: S4Sm-OFP with NB10Sm-GFP, $c l p X-$ OFP with NB10Sm-GFP and exoP-OFP with NB10Sm-GFP. Colonization and initial cell densities were as described in the Materials and Methods. A) Growth of sessile $P$. inhibens cells (with NB10Sm) in a co-culture system and a monoculture control. B) Growth of planktonic P. inhibens cells (with NB10Sm) in a co-culture system and a monoculture control. The data presented are average of two independent experiments and each independent experiment has three replicates. Error bars represent one standard deviation. (PDF $362 \mathrm{~kb}$ )

Additional file 7: Competition assay between $P$. inhibens S4Sm strains and $V$. anguillarum NB10Sm without pre-colonization by $P$. inhibens. The mixed cultures are S4Sm-OFP with NB10Sm-GFP, clpX-OFP with NB10Sm-GFP and exoP-OFP with NB10Sm-GFP. A) Single channel and merged confocal microscopy images of mixed biofilm development by OFP-producing strains ( $\mathrm{S} 4 \mathrm{Sm}$, clpX mutant or exoP mutant) and GFP-producing $V$. anguillarum NB10Sm-GFP on the surface of glass coverslip at $48 \mathrm{~h}$. The data presented is from a representative experiment of two independent experiments. B) Growth of sessile NB10Sm in co-culture system with different Phaeobacter strains. C) Comparison of growth of sessile $V$. anguillarum (NB10Sm) in different co-culture system and monoculture control. D) Growth of planktonic V. anguillarum (NB10Sm) in co-culture system with different Phaeobacter strains. E) Comparison of growth of planktonic $V$. anguillarum (NB10Sm) in different co-culture system and monoculture control. The data presented are average of two independent experiments and each independent experiment has three replicates. Error bars represent one standard deviation. (PDF $1811 \mathrm{~kb}$ )

Competing interests

The authors declare that they have no competing interests.

Authors' contributions

WZ and DRN designed the study. WZ created the strains used in this study. WZ performed most of the assays. CD performed the TDA purification assays under the supervision of DR, and MK performed the oyster larvae challenge assays under the supervision of MCG. WZ and DRN wrote the paper with contributions and editing by MCG and DR. Formatting of the paper was done by WZ and DRN. All authors have read and approved the final version of manuscript. 


\section{Acknowledgements}

We thank the personnel at the Blount Shellfish Hatchery at Roger Williams University for providing larval oysters. We also thank Petra Tielen (Institute of Microbiology, Universität Braunschweig) for the gift of the plasmids pRhokHi-2FbFP, pRhokHi-2, and pBBR1MCS4. Ralph Elston provided RE22 and Katherine Boettcher for providing CV919-312.

\section{Author details}

'Department of Cell and Molecular Biology, University of Rhode Island, 120 Flagg Rd., Kingston, RI 02881, USA. ${ }^{2}$ Biomedical and Pharmaceutical Sciences, University of Rhode Island, Kingston, RI 02881, USA. ${ }^{3}$ Fisheries, Animal and Veterinary Sciences, University of Rhode Island, Kingston, RI 02881, USA. ${ }^{4}$ Present Address: Department of Microbiology and Immunology, Harvard Medical School, Boston, MA 02115, USA. ${ }^{5}$ Present Address: Department of Chemistry and Biochemistry, University of Massachusetts Dartmouth, Darmouth, MA 02747, USA. ${ }^{6}$ Present Address: Department of Aquaculture, Faculty of Agriculture, Universiti Putra Malaysia, 43400 Serdang, Selangor, Malaysia.

Received: 14 July 2015 Accepted: 22 December 2015

Published online: 05 January 2016

\section{References}

1. Austin B, Austin DA. Bacterial Fish Pathogens. Disease of Farmed and Wild Fish. 5th ed. New York, NY: Springer; 2012

2. Paillard C, Le Roux F, Borrego JJ. Bacterial disease in marine bivalves, a review of recent studies: trends and evolution. Aquat Liv Res. 2004;17(4):477-98.

3. Maloy AP, Ford SE, Karney RC, Boettcher KJ. Roseovarius crassostreae, the etiological agent of Juvenile Oyster Disease (now to be known as Roseovarius Oyster Disease) in Crassostrea virginica. Aquaculture. 2007;269(1):71-83.

4. Elston RA, Hasegawa H, Humphrey KL, Polyak IK, Hase CC. Re-emergence of Vibrio tubiashii in bivalve shellfish aquaculture: severity, environmental drivers, geographic extent and management. Dis Aquat Organ. 2008;82(2):119-34

5. Boettcher KJ, Geaghan KK, Maloy AP, Barber BJ. Roseovarius crassostreae sp. nov., a member of the Roseobacter clade and the apparent cause of juvenile oyster disease (JOD) in cultured Eastern oysters. Internat J Syst Evol Microbiol. 2005;55(Pt 4):1531-7.

6. Cabello FC. Heavy use of prophylactic antibiotics in aquaculture: a growing problem for human and animal health and for the environment. Environ Microbiol. 2006;8(7):1137-44.

7. Bachère E. Anti-infectious immune effectors in marine invertebrates: potential tools for disease control in larviculture. Aquaculture. 2003;227(1):427-38.

8. Wang YB, Li JR, Lin J. Probiotics in aquaculture: challenges and outlook. Aquaculture. 2008;281(1):1-4.

9. Balcazar JL, de Blas I, Ruiz-Zarzuela I, Cunningham D, Vendrell D, Muzquiz JL. The role of probiotics in aquaculture. Vet Microbiol. 2006;114(3-4):173-86.

10. Decamp O, Moriarty DJW, Lavens P. Probiotics for shrimp larviculture: review of field data from Asia and Latin America. Aquacul Res. 2008;39(4):334-8.

11. D'Alvise PW, Lillebo S, Prol-Garcia MJ, Wergeland HI, Nielsen KF, Bergh O, et al. Phaeobacter gallaeciensis reduces Vibrio anguillarum in cultures of microalgae and rotifers, and prevents vibriosis in cod larvae. PloS One. 2012;7(8):e43996.

12. D'Alvise PW, Melchiorsen J, Porsby CH, Nielsen KF, Gram L. Inactivation of Vibrio anguillarum by attached and planktonic Roseobacter cells. Appl Environ Microbiol. 2010;76(7):2366-70.

13. Bruhn JB, Nielsen KF, Hjelm M, Hansen M, Bresciani J, Schulz S, et al. Ecology, inhibitory activity, and morphogenesis of a marine antagonistic bacterium belonging to the Roseobacter clade. Appl Environ Microbiol. 2005;71(11):7263-70

14. Gram L, Melchiorsen J, Bruhn JB. Antibacterial activity of marine culturable bacteria collected from a global sampling of ocean surface waters and surface swabs of marine organisms. Mar Biotechnol (NY). 2010;12(4):439-51.

15. Wietz M, Gram L, Jørgensen B, Schramm A. Latitudinal patterns in the abundance of major marine bacterioplankton groups. Aquat Microb Ecol. 2010; 61(2):179-189.
16. Karim M, Zhao W, Nelson DR, Rowley D, Marta Gomez-Chiarri. Probiotic strains for shellfish aquaculture: protection of Eastern oyster, Crassostrea virginica, larvae and juveniles against bacterial. J Shell Res 2013; 32(2):401-408.

17. Porsby $\mathrm{CH}$, Nielsen KF, Gram L. Phaeobacter and Ruegeria species of the Roseobacter clade colonize separate niches in a Danish Turbot (Scophthalmus maximus)-rearing farm and antagonize Vibrio anguillarum under different growth conditions. Appl Environ Microbiol. 2008;74(23):7356-64.

18. Prado S, Montes J, Romalde JL, Barja JL. Inhibitory activity of Phaeobacter strains against aquaculture pathogenic bacteria. Internat Microbiol: the official journal of the Spanish Society for Microbiology. 2009;12(2):107-14.

19. Belas R, Horikawa E, Aizawa S, Suvanasuthi R. Genetic determinants of Silicibacter sp. TM1040 motility. J Bacteriol. 2009;191(14):4502-12.

20. Verschuere L, Rombaut G, Sorgeloos P, Verstraete W. Probiotic bacteria as biological control agents in aquaculture. Microbiol Mol Biol Rev. 2000;64(4):655-71

21. Geng H, Bruhn JB, Nielsen KF, Gram L, Belas R. Genetic dissection of tropodithietic acid biosynthesis by marine roseobacters. Appl Environ Microbiol. 2008;74(5):1535-45.

22. Liang L: Investigation of Secondary Metabolites of North Sea Bacteria: Fermentation, Isolation, Structure Elucidation and Bioactivity. Doctoral Dissertation, University of Göttingen 2003.

23. Thole S, Kalhoefer D, Voget S, Berger M, Engelhardt $T$, Liesegang $H$, et al. Phaeobacter gallaeciensis genomes from globally opposite locations reveal high similarity of adaptation to surface life. ISME J. 2012;6(12):2229-44.

24. Berger M, Brock NL, Liesegang H, Dogs M, Preuth I, Simon M, et al. Genetic analysis of the upper phenylacetate catabolic pathway in the production of tropodithietic acid by Phaeobacter gallaeciensis. Appl Environ Microbiol. 2012;78(10):3539-51.

25. Baker TA, Sauer RT. ClpXP, an ATP-powered unfolding and protein-degradation machine. Biochim Biophys Acta. 2012;1823(1):15-28.

26. Camberg JL, Hoskins JR, Wickner S. The interplay of ClpXP with the cell division machinery in Escherichia coli. J Bacteriol. 2011;193(8):1911-8.

27. Holtman CK, Chen Y, Sandoval P, Gonzales A, Nalty MS, Thomas TL, et al. High-throughput functional analysis of the Synechococcus elongatus PCC 7942 genome. DNA Res. 2005;12(2):103-15.

28. Shiwa Y, Yoshikawa H, Tanaka T, Ogura M. Bacillus subtilis degSU operon is regulated by the ClpXP-Spx regulated proteolysis system. J Biochem. 2015;157(5):321-30.

29. Penesyan A, Gillings M, Paulsen IT. Antibiotic discovery: combatting bacterial resistance in cells and in biofilm communities. Molecules. 2015;20(4):5286-98.

30. Aziz RK, Bartels D, Best AA, DeJongh M, Disz T, Edwards RA, et al. The RAST Server: rapid annotations using subsystems technology. BMC Genomics. 2008;9:75.

31. Berger M, Neumann A, Schulz S, Simon M, Brinkhoff T. Tropodithietic acid production in Phaeobacter gallaeciensis is regulated by $\mathrm{N}$-acyl homoserine lactone-mediated quorum sensing. J Bacteriol. 2011;193(23):6576-85.

32. Porsby $\mathrm{CH}$, Webber MA, Nielsen KF, Piddock LJ, Gram L. Resistance and tolerance to tropodithietic acid, an antimicrobial in aquaculture, is hard to select. Antimicrob Agents Chemother. 2011;55(4):1332-7.

33. Wiegand I, Hilpert K, Hancock RE. Agar and broth dilution methods to determine the minimal inhibitory concentration (MIC) of antimicrobial substances. Nature Protocols. 2008:3(2):163-75.

34. Varina M, Denkin SM, Staroscik AM, Nelson DR. Identification and characterization of Epp, the secreted processing protease for the Vibrio anguillarum EmpA metalloprotease. J Bacteriol. 2008;190(20):6589-97.

35. Sezonov G, Joseleau-Petit D, D'Ari R. Escherichia coli physiology in Luria-Bertani broth. J Bacteriol. 2007;189(23):8746-9.

36. Denkin SM, Nelson DR. Regulation of Vibrio anguillarum empA metalloprotease expression and its role in virulence. Appl Environ Microbiol. 2004;70(7):4193-204

37. Milton DL, O'Toole R, Horstedt P, Wolf-Watz H. Flagellin A is essential for the virulence of Vibrio anguillarum. J Bacteriol. 1996;178(5):1310-9.

38. Li L, Mou X, Nelson DR. HlyU is a positive regulator of hemolysin expression in Vibrio anguillarum. J Bacteriol. 2011;193(18):4779-89.

39. Buddruhs N, Pradella S, Goker M, Pauker O, Pukall R, Sproer C, et al. Molecular and phenotypic analyses reveal the non-identity of the Phaeobacter gallaeciensis type strain deposits CIP 105210 T and DSM 17395. International J Syst Evol Microbiol. 2013;63(Pt 11):4340-9.

40. Rock JL, Nelson DR. Identification and characterization of a hemolysin gene cluster in Vibrio anguillarum. Infect Imm. 2006;74(5):2777-86. 
41. Mou X, Spinard EJ, Driscoll MV, Zhao W, Nelson DR. H-NS is a negative regulator of the two hemolysin/cytotoxin gene clusters in Vibrio anguillarum. Infect Imm. 2013;81(10):3566-76.

42. Rao D, Skovhus T, Tujula N, Holmstrom C, Dahllof I, Webb JS, et al. Ability of Pseudoalteromonas tunicata to colonize natural biofilms and its effect on microbial community structure. FEMS Microbiol Ecol. 2010;73(3):450-7.

Submit your next manuscript to BioMed Central and we will help you at every step:

- We accept pre-submission inquiries

- Our selector tool helps you to find the most relevant journal

- We provide round the clock customer support

- Convenient online submission

- Thorough peer review

- Inclusion in PubMed and all major indexing services

- Maximum visibility for your research

Submit your manuscript at www.biomedcentral.com/submit 